\title{
Aplicação foliar de silício e a redução de ocorrência de doenças fúngicas na cultura do morangueiro
}

\author{
Alcemir Nabir Kowal', Douglas André Wurz', Antonio Felippe Fagherazzi², Daniele Moreira Ribeiro', \\ Mauro Nizer' \\ ' Instituto Federal de Educação, Ciência e Tecnologia de Santa Catarina- IFSC Campus Canoinhas \\ E-mail: alcemirkowal@gmail.com; douglas.wurz@ifsc.edu.br; dannyribeiro8@gmail.com; mauro.nizer@ifsc.edu.br \\ ${ }^{2}$ Centro de Ciências Agroveterinárias da Universidade do Estado de Santa Catarina - CAV/UDESC \\ E-mail: antonio.fagherazzi@gmail.com
}

\section{Resumo}

Diversas doenças fúngicas podem ocorrer na cultura do morangueiro, dentre as quais a micosferela, a antracnose e o mofo cinzento. O silício é um mineral que atua como agente fertilizante e defensivo agrícola. A fim de reduzir o uso de agrotóxicos, esse trabalho teve por objetivo avaliar o efeito de diferentes doses de silício no controle das principais doenças fúngicas do morangueiro cultivado no Planalto Norte Catarinense. $O$ trabalho foi realizado na área experimental do IFSC - Campus Canoinhas. Os tratamentos consistiram na aplicação de cinco diferentes doses de silício, por meio do produto Agrisil ${ }^{\circledR}(99 \% \mathrm{Si})$. Foram realizadas aplicações com diferentes doses do produto, I00, 200, 300 e 400 g (i.a. silício)/ I 00L água. As avaliações da incidência e severidade das doenças foram realizadas, e as doses de 300g e $400 \mathrm{~g}$ (i.a. silício)/ I 00L água proporcionaram redução na ocorrência da micosferela e mofo cinzento. Assim, o uso de silício apresenta-se como uma alternativa para o controle dessas doenças, reduzindo os impactos ambientais e o efeito nocivo ao trabalhador rural.

Palavras-chave: Botrytis cinérea. Colletotrichum fragariae. Fragaria x ananassa Duchesne. Mycosphaerella fragariae.

\section{Abstract}

\section{Silicon foliar application reduces the occurrence of fungal diseases in strawberry crop}

Several fungal diseases can occur in strawberry crop, including mycosferela, anthracnose and gray mold. Silicon is a mineral that acts as a fertilizer and agricultural defensive agent. In order to reduce the use of pesticides, this study aimed to evaluate the effect of different doses of silicon on the control of the main fungal diseases of strawberry cultivated in the Northern Santa Catarina Plateau. The work was carried out in the experimental area of IFSC Campus Canoinhas, through treatments that consisted of the application of five different doses of silicon, using Agrisil ${ }^{\circledR}(99 \% \mathrm{Si})$. Applications were made with different doses of the product, 100, 200, 300 and $400 \mathrm{~g}$ (i.e. silicon) / 100L water. Assessments of disease incidence and severity were performed, and doses of 300g and 400g (i.a. silicon) / 100L water provided a reduction in the occurrence of mycosferela and gray mold. Thus, the use of silicon presents itself as an alternative for the control of these diseases, reducing the environmental impacts and the harmful effect to the rural worker.

Keywords: Botrytis cinerea; Colletotrichum fragariae; Fragaria x ananassa Duchesne. Mycosphaerella fragariae. 


\section{Introdução}

O morangueiro (Fragaria $x$ ananassa Duchesne) é explorado comercialmente em todos os continentes (JORGE et al, 2008). O principal fator para a exploração comercial da cultura é justificado pela elevada produtividade e rentabilidade econômica, quando comparada a outras, como o milho e a soja (REICHERT; MADAIL, 2003; SANHUEZA et al, 2005; THIMOTEO et al, 2006). Por ser uma importante fonte de vitamina $\mathrm{C}$, antocianinas e atividades antioxidantes, o consumo do morango pode contribuir para a prevenção de doenças do coração (COCCO et al, 20I5).

A superfície mundial cultivada com morangueiro passou de 314,8 mil hectares em 2000 para 395,8 em 2017, e a produção passou de 4,4 para 9,2 milhões de toneladas para o mesmo período (FAOSTAT, 2019). Durante esse período de 17 anos, verificou-se um incremento de $25,7 \%$ na superfície cultivada, e de $109 \%$ na produção.

No Brasil, entre as espécies que compõe o grupo das pequenas frutas, o morangueiro lidera o ranking de cultivo em ampla escala geográfica, sendo de grande importância econômica às regiões produtoras, especialmente à agricultura familiar. Para aumentar sua qualidade e produtividade, o fornecimento de nutrientes às plantas torna-se uma alternativa que apresenta retorno benéfico (FAGHERAZZI et al, 20I7b). Segundo Fagherazzi et al (2017a), a produção brasileira de morango gira em torno de 155 mil toneladas em uma superfície cultivada com 4.300 hectares, gerando uma produtividade média de 36,I toneladas por hectare, todavia, pesquisas já realizadas demonstraram produtividades superiores as 50 toneladas por hectare (STRASSBURGER et al, 20Il; GUIMARÃES et al, 20I5).

A cultura do morangueiro é suscetível ao ataque de fungos, os quais causam deformidades em seus frutos e folhas, reduzindo tanto a produtividade das plantas quanto a qualidade dos frutos. A doença foliar com maior índice de ocorrência é a mancha de micosferela (Mycosphaerella fragariae), fungo que ataca principalmente as folhas da cultura, reduzindo a área foliar fotossinteticamente ativa. $O$ patógeno apresenta condições ótimas de desenvolvimento sob condições de temperatura entre 22 e $26^{\circ} \mathrm{C}$, alta umidade relativa do ar e excesso de nitrogênio (COSTA; VENTURA; LOPES, 20I I).

A antracnose (Colletotrichum fragariae) é uma das principais doenças do morangueiro no Brasil. Ao infeccionar os frutos, os sintomas variam conforme a formação dos mesmos. Quando novos, apresentam uma podridão seca e escurecem, tornando-se posteriormente mumificados. Os frutos em estádios avançados de desenvolvimento, por sua vez, apresentam uma podridão marrom e, se maduros podem apodrecer parcial ou totalmente (REIS; COSTA, 20I I).

Em relação a podridões de frutos, um dos maiores problemas é o mofo cinzento ou podridão (Botrytis cinerea). Os frutos maduros ou em amadurecimento são mais suscetíveis à infecção do fungo, entretanto, podem ser infeccionados em qualquer fase do desenvolvimento. Os frutos infectados caracterizam-se por apresentarem uma massa cinzenta em sua superfície e a disseminação do agente patogênico ocorre principalmente através do vento (REIS; COSTA, 20I I).

Desde o início do século $X X$, publicações demonstraram que o silício, ao ser empregado como fertilizante para as plantas, apresentava efeitos favoráveis superiores aos sais potássicos da época. Atualmente, cientistas ao redor do mundo examinam a forma de atuação dos silicatos sobre as plantas e doenças fúngicas, comprovando os benefícios destes quando empregados na vegetação em forma de fertilizantes ou defensivos agrícolas (LIMA FILHO, 2009). O silício se acumula nos tecidos de plantas e pode melhorar o desenvolvimento de várias espécies vegetais, além de proporcionar maior resistência a pragas e doenças, seja pela promoção de uma barreira mecânica ou pelo acúmulo de compostos fenólicos, que impedem a infecção por patógenos e diminuem a palatabilidade aos insetos praga (GOUSSAIN, et al, 2002). Nesse contexto, o presente trabalho teve como objetivo avaliar o efeito de diferentes doses de silício no controle de doenças fúngicas em morangueiros cultivados no Planalto Norte Catarinense.

\section{Material e Métodos}

O experimento foi conduzido na área experimental do Instituto Federal de Santa Catarina, IFSC - Campus Canoinhas, na Região do Planalto Norte Catarinense, localizado a $26^{\circ}$ II' S, 50 $22^{\prime}$ ' W e a uma altitude de 1200 metros em relação ao nível do mar. 
As mudas de morangueiro da cultivar Pircinque eram do tipo 'torrão', e foram produzidas em bandejas de 72 células, com volume de substrato de $55 \mathrm{ml}$ para cada muda. Essas mudas foram produzidas por um viveiro comercial, cuja atividade de produção de plantas vegetais é reconhecida pelo Ministério da Agricultura, Pecuária e Abastecimento (MAPA). A cultivar Pircinque é classificada como uma cultivar de 'dia curto', e foi desenvolvida na Itália pelo Consiglio per la Ricerca in Agricoltura e L'Analisi Dell'Economia Agraria - Centro di Ricerca Olivicoltura, Frutticoltura e Agrumicoltura (CREA-OFA-FRF), que por meio da 'Convenção para a experimentação e difusão do material genético de morangueiro italiano no Brasil', foi introduzida pelo Centro de Ciências Agroveterinárias da Universidade do Estado de Santa Catarina (CAV/UDESC), sendo essa a instituição que realiza a difusão da cultivar Pircinque em todo território brasileiro.

O sistema de cultivo adotado para a experimentação foi o convencional no solo, em sistema de túnel alto revestido com filme de polietileno transparente, com I 50 micras de espessura. No solo revolvido foi realizada a calagem de acordo com a interpretação e recomendação utilizada nos estados de Santa Catarina e Rio Grande do Sul, para a cultura do morangueiro. Com auxílio de uma enxada rotativa encanteiradora, foram feitos os canteiros com cerca de $90 \mathrm{~cm}$ de largura e 20 centímetros de altura, onde os mesmos foram revestidos com filme de polietileno de coloração preta, com 25 micras de espessura, objetivando-se evitar o contato das frutas ao solo, evitar o crescimento de plantas daninhas e manter a umidade no solo. Antes do plantio as mudas foram classificadas e padronizadas com três folhas compostas. Posteriormente elas foram plantadas em junho de 2019 , com espaçamento de 30 centímetros entre linhas de plantio e plantas, configurando-se três linhas de plantio para cada canteiro. O sistema de irrigação e fertirrigação era via gotejo, através de fitas gotejadoras alocadas entre o solo e o filme que revestia os canteiros.

Os tratamentos consistiram na aplicação foliar de cinco doses de silício, sendo: TI - Testemunha (sem aplicação de silício); T2 - 100 g (i.a. silício) / 100 L água; T3 - 200 g (i.a. silício) / 100 L água; T4 - 300 g (i.a. silício) / 100 L água; T5 - $400 \mathrm{~g}$ (i.a. silício) / 100 L água. O produto comercial Agrisil ${ }^{\circledR}$ ( $99 \%$ Si) foi utilizado como fonte de Si. As aplicações foram realizadas a cada 21 dias, durante o período compreendido entre agosto de 2018 a fevereiro de 2019 , com auxílio de um pulverizador costal manual, aplicando-se a solução de calda via foliar, até o ponto de escorrimento.

As análises de incidência e severidade da Micosferela foram realizadas quinzenalmente. Para a avaliação dos níveis de incidência, a ausência ou presença de sintomas da doença foi determinada, ao passo que para avaliar a severidade fez-se o uso da escala diagramática proposta por Mazaro et al (2006). A quantificação (\%) da incidência de mofo cinzento e antracnose foi obtida no momento da colheita, por meio da avaliação dos frutos colhidos de cada unidade experimental. O resultado foi obtido através da razão do total de frutos avaliados e dos que possuíam sintomas das doenças. A severidade (\%) dessas doenças não foi avaliada por não apresentarem escala diagramática validada.

O delineamento utilizado foi de blocos casualizados com cinco tratamentos, três repetições e dez plantas por unidade experimental. Os resultados obtidos foram submetidos à análise de variância (ANOVA) e, quando significativo, as médias foram comparadas entre si pelo teste de Tukey a $5 \%$ de probabilidade de erro, através do software Sisvar 4.I.

\section{Resultados e Discussão}

Após a aplicação de diferentes doses do produto à base de silício como forma de controle de doenças fúngicas, foi observado a ação deste no controle de doenças nos frutos (antracnose e a podridão) e nas folhas (micosferela).

$\mathrm{Na}$ análise realizada de incidência das doenças nos frutos verificou-se que, para a antracnose (\%), não houve efeito das aplicações das diferentes doses de silício (Tabela I). Já para a podridão de frutos, observou-se o efeito da aplicação de silício no morangueiro (Tabela I). Verificou-se que as doses de $300 \mathrm{~g}$ e $400 \mathrm{~g}$ (i.a. silício)/ $100 \mathrm{~L}$ água foram as que proporcionaram melhores resultados em relação a redução da ocorrência de podridão. 


\begin{tabular}{ccc}
\hline & \multicolumn{2}{c}{ Incidência nos Frutos } \\
\cline { 2 - 3 } Tratamento & $\begin{array}{c}\text { Antracnose } \\
\%\end{array}$ & $\begin{array}{c}\text { Podridão } \\
\%\end{array}$ \\
\hline Testemunha & $6,2 \mathrm{~ns}$ & $35,2 \mathrm{a}$ \\
$\mathbf{1 0 0} \mathbf{g}$ (i.a. silício)/ 100L água & 5,8 & $22,8 \mathrm{~b}$ \\
$\mathbf{2 0 0} \mathbf{g}$ (i.a. silício)/ / 00L água & 6,6 & $20,6 \mathrm{~b}$ \\
$\mathbf{3 0 0} \mathbf{g}$ (i.a. silício)/ / 00L água & 5,9 & $14,1 \mathrm{c}$ \\
$\mathbf{4 0 0} \mathbf{g}$ (i.a. silício)/ / 00L água & 6,7 & $14,3 \mathrm{c}$ \\
\hline $\mathbf{C V}(\%)$ & 21,5 & 14,9 \\
\hline
\end{tabular}

*Médias seguidas pela mesma letra, na coluna, não diferem significativamente entre si, pelo teste de Tukey a $5 \%$.

O efeito das diferentes doses de silício na incidência e severidade de micosferela do morangueiro 'Pircinque' estão descritos na Tabela 2. Observou-se o efeito da aplicação do silício na redução da incidência e severidade da mancha de micosferela.

Tanto para a incidência quanto para a severidade, observou-se que as doses de $300 \mathrm{~g}$ e $400 \mathrm{~g}$ (i.a. silício)/ I00L apresentam melhores efeitos em relação a redução da incidência e severidade da micosferela. Para as doses de $300 \mathrm{~g}$ e $400 \mathrm{~g}$ (i.a. silício)/ $/ 00 \mathrm{~L}$, verificou-se a incidência de 35,8 e 33,5\%, respectivamente, ao passo que para a severidade (\%), observou-se valores de $13,5 \%$ e $12,7 \%$, respectivamente. Segundo Dann e Muir (2002), o silício tem sido utilizado na supressão de muitas doenças de plantas, devido ao seu acúmulo no tecido epidérmico, protegendo a cutícula da folha e a parede celular, aumentando assim a sua resistência à degradação por enzimas liberadas pelos fungos.

Tabela 2. Efeito da aplicação de diferentes doses de silício na incidência e severidade da micosferela em folhas do morangueiro 'Pircinque' cultivado no Planalto Norte Catarinense, Canoinhas, safra 2018/2019.

\begin{tabular}{|c|c|c|}
\hline \multirow{4}{*}{ Tratamento } & \multicolumn{2}{|c|}{ Doenças Folhas Morangueiro } \\
\hline & \multicolumn{2}{|c|}{ Micosferela } \\
\hline & Incidência & Severidade \\
\hline & $\%$ & $\%$ \\
\hline Testemunha & $75,4 \mathrm{a}$ & $25,8 \mathrm{a}$ \\
\hline 100 g (i.a. silício)/ $100 \mathrm{~L}$ água & $70,5 \mathrm{a}$ & $23,9 \mathrm{a}$ \\
\hline $200 \mathrm{~g}$ (i.a. silício)/ $100 \mathrm{~L}$ água & $55,9 \mathrm{~b}$ & $20, I$ a \\
\hline $300 \mathrm{~g}$ (i.a. silício)/ / 00L água & $35,8 c$ & $13,5 \mathrm{~b}$ \\
\hline $400 \mathrm{~g}$ (i.a. silício)/ $100 \mathrm{~L}$ água & $33,5 c$ & $12,7 \mathrm{~b}$ \\
\hline CV (\%) & 13,2 & 25,6 \\
\hline
\end{tabular}

*Médias seguidas pela mesma letra, na coluna, não diferem significativamente entre si, pelo teste de Tukey a 5\%.

No último relatório (2013-20I5) do Programa de Análise de Resíduos de Agrotóxicos em Alimentos (PARA) disponibilizado pela Anvisa, 157 amostras de morango foram analisadas e, destas, apenas 43 foram consideradas satisfatórias (não foram detectados resíduos dos agrotóxicos pesquisados em duas amostras, e 4 I amostras apresentaram resquícios dentro do Limite Máximo de Resíduos - LMR - permitido). Nesta mesma avaliação, 4 I das amostras excederam o permitido pelo LMR e outras I I 0 apontaram o uso de agrotóxicos não autorizados para a cultura do morangueiro. Assim, mais de $72 \%$ das amostras analisadas estavam em desconformidade com o estabelecido pela Anvisa, o que pode ser considerado inseguro para a saúde do consumidor (ANVISA, 20I6).

Nesse sentido, a busca por alternativas mais sustentáveis de controle das principais doenças fúngicas torna-se necessária, com resultados satisfatórios do uso do silício na prevenção das principais doenças fúngicas da cultura do morangueiro. 


\section{Considerações Finais}

As doses de 300g e 400g (i.a. silício)/ I 00 Lágua reduziram a ocorrência da micosferela e do mofo cinzento, contudo, não apresentando efeito sobre a antracnose.

O manejo das principais doenças fúngicas que atacam a cultura do morangueiro, além da formação mais completa dos discentes que acompanharam o desenvolvimento do presente trabalho, são fatores que devem incentivar o fomento e a realização de estudos similares para a manutenção e o incremento da sustentabilidade da atividade.

Uma das possibilidades para a redução ou substituição do uso de produtos químicos no controle de pragas e doenças no morangueiro é o uso do silício (Si).

\section{Referências}

AGENCIA NACIONAL DE VIGILÂNCIA SANITÁRIA - ANVISA. Programa de Análises de Resíduos de Agrotóxicos em Alimentos PARA 2016. Disponível em: http://portal.anvisa.gov.br/documents/l1/215/0/Relat\%C3\%B3rio+PARA+2013-20I5_VERS\%C3\%83O-FINAL.pdf/494cd7c5-5408-4e6a-b0e5-5098cbf759f8. Acesso em: I0. Junho de 2019.

$\mathrm{COCCO}, \mathrm{C}$. et al. Effects of site and genotype on strawberry fruits quality traits and bioactive compounds. Journal of Berry Research, Amsterdam, v.5, I45-155, 2015.

COSTA, H.; VENTURA, J.; LOPES, U. Manejo integrado de doenças do morangueiro. In: CONGRESSO BRASILEIRO DE OLERICULTURA, 5I. Horticultura Brasileira 29. Viçosa: 201 I.

DANN, E.K.; MUIR, S. Peas grown in media with elevated plant-available silicon levels have higher activities of chitinases and $\square$-I,3-glucanase, are less susceptible to a fungal leaf spot pathogen and accumulate more foliar silicon. Australian Plant Pathology, v. 3I, p. 9-13, 2002.

FAGHERAZZI, A.F. et al. Strawberry production progress in Brazil. Acta Horticulturae, Haia, v. I I56, n. I, 937-940, 2017 a.

FAGHERAZZI, A.F et al. Adaptabilidade de novas cultivares e seleções de morangueiro para o Planalto Sul Catarinense. 2017. 147p. Tese de Doutorado - Produção Vegetal, Universidade do Estado de Santa Catarina, Lages, 20I7b.

FAOSTAT. Food and Agriculture Organisation Statistics Database. 2019. Produção mundial de pequenas frutas. Disponível em: http://www.fao.org/faostat/en/\#compare. Acessado em:23 de out. 2019.

GOUSSAIN, L. et al. Efeito da aplicação de silício em plantas de milho no desenvolvimento biológico da lagarta-do-cartucho Spodoptera frugiperda (J. E. Smith) (Lepidoptera: Noctuidae). Neotropical Entomology, v. 3I, n. 2, p. 305-3I0, 2002.

GUIMARAES, A.G. et al. Productive potential of strawberry cultivars. Revista Brasileira de Fruticultura, Jaboticabal, v. 37, n. I, p. II2-I20, 2015.

JORGE, Z.L.C. et al. Controle de podridão pós-colheita de morangos "Camarosa" tratados com luz germicida UV-C. In: XX Congresso Brasileiro de Fruticultura, Vitória. Anais...Vitória/ES, 2008.

LIMA FILHO, O. F. História e Uso do Silicato de Sódio na Agricultura. ${ }^{\text {a }}$ Ed. Embrapa. Dourados, Editora Embrapa, 115 p. 2009.

MAZARO, S.M.et al.Escala diagramática para avaliação da severidade da mancha-de-micosferela em morangueiro. Ciência Rural, Santa Maria, v. 36, n. 2, p. 648-652, 2006.

REICHERT, L.J.; MADAIL, J.C.M. Aspectos Socioeconômicos In: SANTOS, A.M. (Ed.); MEDEIROS, A.R.M. (ed.). Morango; produção. Brasília: Embrapa Informação Tecnológica, p. 35-38, 2003.

REIS, A.; COSTA, H. Principais doenças do morangueiro no Brasil e seu controle. Brasília: Embrapa, 20I I.

SANHUEZA, R. et al. Sistema de produção de morango para mesa na Região da Serra Gaúcha e Encosta Superior do Nordeste. Brasília: Embrapa Uva e Vinho, 2005. Disponível em: http://sistemasdeproducao.cnptia.embrapa. br/FontesHTML/Morango/MesaSerraGaucha/importancia.htm Acesso em: 18 out. 2019.

STRASSBURGER, A.S. et al. Crescimento do morangueiro: influência da cultivar e da posição da planta no canteiro. Ciência Rural, Santa Maria, v.4I, n.2, 223-226, 201 I.

THIMOTEO, A. et al. Expectativa de retorno e risco da produção de morangos no município de Guarapuava - $\operatorname{Pr} \ln$ : 46 CONGRESSO BRASILEIRO DE OLERICULTURA, Anais... Goiânia, I CD - ROM, 2006. 